\title{
Enhanced DM program in British Columbia's healthcare sector
}

\author{
Theresa Morrison \\ EDMP Administrator for the Hospital Employees' Union, Burnaby, Canada. TMorrison@heu.org \\ Lani deHek \\ British Columbia Nurse's Union, Canada. Idehek@bcnu.org
}

Background: The Healthcare Sector in British Columbia, Canada is comprised of over 110,000 employees covered by four union collective agreements. The overall disability burden for this industry is close to $\$ 300 \mathrm{M}$ annually. The EDMP was negotiated and developed through employer-union partnership. It is a province-wide program that is a component of the four healthcare collective agreements. Implemented in 2012, EDMP supports employees that are absent from work/struggling at work due to occupational or non-occupational illness/injury.

Objectives: To showcase a leading DM best practice, highlighting effective joint union/employer stewardship of a comprehensive DM program for a major industry in British Columbia, Canada.

Methods: Participation in EDMP is required for regular employees who meet one of the following criteria:

- shift due to illness or injury resulting from a work-related event

- consecutive shifts due to a non work-related illness or injury.

Comprehensive policy and process documents developed collaboratively guide the program, with provincial steering joint committee over-site. Union representatives with DM-specific training support the program, working in collaboration with employer's DM professionals to administer a pro-active, comprehensive case management plan with an overarching principle of early intervention and recovery at work. DM-related issues are removed from the labor-relations realm, with a separate dispute resolution process to address disagreements with case management plans.

Findings: The collaborative partnership between EDMP union reps and employer DM professionals facilitates engagement of injured/ill employee and improves the ability to identify and address return to work barriers: medical, workplace, vocational, personal. The mandatory component of the CA language improves engagement from both union and employer, with reductions in both WCB and LTD claim durations as a positive result. Fewer conflicts regarding DM related issues are an additional benefit.

Conclusion: The EDMP should be used a model of effective union-employer partnership in the management of employee illness/injury and should be replicated in other industries/jurisdictions. 